\title{
Secrets
}

\section{Jeremy Bernstein}

\section{Restricted Data: The History of Nuclear Secrecy in the United States}

by Alex Wellerstein

University of Chicago Press, 528 pp., $\$ 35.00$.

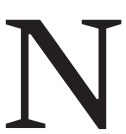

UCLEAR WEAPONS have been shrouded in secrecy from the very beginning. After plutonium was discovered at the University of California in December 1940, researchers led by Glenn Seaborg submitted a pair of letters to the Physical Review. The details of their discovery were withheld from publication until after the war. ${ }^{1}$ Once the project to make a nuclear weapon got underway, secrecy became a very serious matter indeed. The story of these efforts and how they evolved after the war is the subject of Alex Wellerstein's Restricted Data: The History of Nuclear Secrecy in the United States. It is an extremely detailed study. I can tell he has been working on this book for many years because in his acknowledgements he refers to sources who have long been dead. In his introduction, Wellerstein points out that he has never worked on a classified project or held a security clearance. "This no doubt leaves many additional gaps in the story," he observes, "but it also allows me to share what I have found with impunity."

$\mathrm{B}$ EFORE I TURN to a discussion of the book, let me explain why this subject is of special interest to me. In the winter of 1954, it had become clear that by the following year I would obtain my PhD from Harvard. I had passed the qualifying examinations, taken all the required courses, and was well underway with my thesis. I had not given much thought to what I might do next. As it turned out, an assistant professor I knew had heard about a new laboratory opening at the University of California at Berkeley and passed on my details to one of its founders, Edward Teller. I arranged to meet with Teller in Washington at the spring meeting of the American Physical Society. It was only after our meeting that I came to understand why he had started the Lawrence Livermore National Laboratory. Around 1952, Teller began to feel that the researchers at Los Alamos were not working hard enough on nuclear weapons to confront the Soviet Union. He decided to found a rival weapons laboratory. Even if Teller had offered me a job, I doubt that I would have accepted. ${ }^{3}$

After obtaining my degree, I was offered a job that would keep me in Cambridge for at least another year. One year became two and at the end of my second year I was accepted at the Institute for Advanced Study in Princeton. It was around this time that the chairman of the physics department at Harvard, Kenneth Bainbridge, came to me with an offer. Bainbridge had been an important figure at Los Alamos during the war. Robert Oppenheimer had put him in charge of the site in New Mexico where the Trinity test had taken place. ${ }^{4}$ Bainbridge told me that the laboratory was offering summer jobs to young $\mathrm{PhDs}$ and asked if I was interested. I was very interested. Los Alamos had an almost mystical significance for me due to its history and remote location. During our conversation, Bainbridge noted that I would have to pass a security clearance before I could work there.

Wellerstein discusses the history of these clearances in his book and describes how they evolved from informal agreements to the highly structured and rigorous arrangements that I confronted. By 1957, an access authorization known as a Q clearance was required to work in any of the technical divisions at the laboratory. ${ }^{5}$ As the highest level of security clearance, it was a prerequisite for anyone who needed access to classified information connected with nuclear weapons research. The FBI handled all the interviews for the clearance process and contacted many of my friends and neighbors as part of its background checks. ${ }^{6} \mathrm{I}$ was relieved when I received my clearance.

W HEN I ARRIVED at Los Alamos in the summer of 1957, I shared an office with another Harvard postdoc named Kenneth Johnson. There may have been a security notice to the effect that we would only receive classified information on a need-toknow basis. After a couple of days, we realized that no one was giving us any information about anything-including what we should be doing. I decided that we might as well work on our own physics problems and proposed one to Johnson that I had begun to think about. He was a whiz when it came to calculations and soon had the whole thing 
worked out. I went to the head of the theoretical division, J. Carson Mark, and asked what we should do with our result. Mark suggested we write up the work and circulate it as a Los Alamos preprint. A paper like this would show that we were capable of working on non-weapons-related physics at the laboratory.

Not long after I got there, some distinguished theorists began arriving at Los Alamos to work on controlled fusion. This research program was aimed at fusing light elements, such as the isotopes of hydrogen, under controlled conditions to form helium and yield an energetic neutron. It is this kind of reaction that powers the hydrogen bomb. At the time, controlled fusion research was classified. It was only after I obtained my clearance that I was able to listen to a seminar. A little more than a year later, the subject was declassified and the research presented at the Atoms for Peace conference in Geneva, alongside similar work from Great Britain and the Soviet Union. ${ }^{7}$ As it turned out, the Russians had more to teach us than we them. This area of research is discussed in detail by Wellerstein, and his account includes many details I did not know.

Among the theorists who descended on Los Alamos was Francis Low, one of the most brilliant theoretical physicists of his generation. Low also liked to play tennis. We began to play together on a regular basis and even became part of the Los Alamos team. Sometime in late August, Low was forced to skip a match because he was going to Nevada to observe some bomb tests. I knew that Los Alamos was heavily involved in a series of nuclear tests that summer, which I later discovered were known as Operation Plumbbob. No fewer than twenty-nine tests were scheduled to take place between May 29 and October 7. Among them were projects from both Los Alamos and Livermore; the Los Alamos tests were named after scientists and the Livermore tests, after mountains. It had never occurred to me that someone outside the weapons program could watch these tests. Low told me he had been invited by Mark. When I asked Mark if I could accompany Low, he agreed on the condition that I pay for the airfare between Albuquerque and Las Vegas.

On the afternoon of August 30, we boarded a plane for Las Vegas. The Nevada Test Site is located about sixty-five miles north of the city. We were met upon arrival at the airport by a government car that took us at once to a casino. ${ }^{8}$ In hindsight, it seems crazy that above-ground nuclear tests were taking place only sixty-five miles away from a major city. I was told that the mushroom clouds were clearly visible from the casinos. Later that evening we were informed that the test scheduled for the following morning at sunrise was going ahead. After a few hours of sleep we made our way to a concrete bunker to observe the explosion. In the distance I could see the tower that held the device. We were given dark lenses to hold over our glasses and instructed to look away and count to ten before turning around. When I turned around, the clouds were glowing and the nearby hill was lit up with flame. Next came the shockwave and then finally the sound of the explosion, which almost seemed like an afterthought. I learned later that the device being tested, Smoky, had a yield of forty-four kilotons, around three times the yield of the bomb dropped on Hiroshima.

After a short break, Mark took us on his rounds. The first stop was the tower that had been erected for a Los Alamos device, Galileo. From memory, the tower appeared to be several hundred feet tall. The platform that held the device was accessed by taking a flimsy-looking open elevator most of the way up, and then climbing the rest of the way on an equally flimsy metal ladder. The device itself looked more like a science experiment than a bomb. There were wires protruding from it in all directions and a couple of men working on it attaching yet more wires. I noted a familiar cluc-cluc sound in the background. It was the sound that a pump makes when it creates a vacuum. I wondered why I could hear it on the platform, but since I had no need to know, I did not ask.

After Mark was finished at the tower, we got back in his car and drove to a blockhouse at the edge of the site. When he opened the door I recoiled. On a shelf inside was an array of metal pits. Despite my limited knowledge of nuclear weapons, I was still able to recognize the plutonium cores. Mark took one off the shelf and handed it to me. It was about the size and weight of a bowling ball and warm to the touch. If I had known that the density of plutonium was greater than lead, I would have realized that these were hollow pits. Even so, it would never have occurred to me to ask why.

I had no need to know.

The next morning, we watched the Galileo device explode with a yield of only eleven kilotons. After the initial atomic bombs had been assembled, the designers realized that they could make a much more efficient device if they combined fission and fusion. This is not what is typically referred to today as a hydrogen bomb, but something in between. Before detonation, a partial vacuum is created in a hollow pit. A mixture of deuterium and tritium gas is then injected. When the fission device detonates, these nuclei fuse to form helium, emitting a neutron. This neutron is sufficiently energetic that it can fission uranium-238, and this is what boosts the bomb. The Galileo test was a new version of this device. After the test, I began the long drive back east with Low. We never spoke about the experience again, either during that journey, or in the years that followed. Low died in 2007, so I will never have the chance to ask him what he knew when he was watching these tests.

I had no need to know.

As part of the security measures in wartime Los Alamos, Wellerstein describes how a "system of colored badges distinguished the different categories of knowledge one might be entitled to." If the badge was white, the bearer 
was permitted access to restricted data on a need-to-know basis. ${ }^{10}$ Oppenheimer introduced a weekly colloquium for all white badge holders. There was also an afternoon tea. The latter tradition was still being observed during my summer at Los Alamos. I remember a British physicist who had been there during the war looking at the people in attendance and remarking that "the days of the great Los Alamos teas are over." There had once been an abundance of present and future Nobel Prize winners at these events. Those days were long gone.

\section{A} S WELLERSTEIN OBSERVES, secrecy has been part of the nuclear ethos almost since the discovery of the neutron by James Chadwick in 1932. A year later, the Hungarian-born polymath and physicist Leo Szilard sensed the implications of the changing political climate in Germany and moved to England. Szilard was out for a walk in London when he was struck by an idea. Suppose that there were a process in which, say, two energetic neutrons were produced. Fission is just such a process, but it would not be discovered until the end of 1938. Once emitted, the two neutrons could produce more neutrons as part of a chain reaction. Szilard realized that the reaction could be explosive and immediately filed a secret patent application, which was granted in 1936. After moving to the United States several years later, Szilard drafted a confidential letter to President Franklin D. Roosevelt, which was signed by Albert Einstein, warning that the Germans might attempt to make an atomic bomb. ${ }^{11}$

As Wellerstein notes, the whole question of nuclear secrecy took on a different character after the creation of the United States Atomic Energy Commission (AEC) in 1946. The Smyth Report is a good example of the somewhat random character of information releases prior to the AEC. Written by the physicist Henry DeWolf Smyth and dated July 1, 1945, the report preceded not only the attacks on Hiroshima and Nagasaki, but also the first Trinity test. It was compiled at the request of General Leslie Groves, head of the Manhattan Project. He realized that a proper accounting would be needed to show how the vast sums of money allocated to the project had been spent. Smyth was chosen to write it. In the end, the report was not released until several days after the bombing on Nagasaki. It quickly created controversy and there were even claims that it revealed the secret of the atomic bomb. What Smyth really revealed was just how hard it was to produce the materials to make one. The report makes no mention of implosion, for example, but there is a great deal of discussion about the vast enterprise needed to produce plutonium.

Until I read Wellerstein's book, I had forgotten that Hans Bethe wrote an article in the spring of 1950 for Scientific American on the hydrogen bomb..$^{12}$ I knew Bethe well: no one was more scrupulous about restricted data. His article was no exception, but the AEC decided that a figure like Bethe writing on the topic was a revelation in itself. They insisted that several thousand copies of the magazine be destroyed, along with the printing plates.

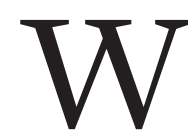

ELLERSTEIN'S ACCOUNT OF A technological transfer that took place around 1956 was of particular interest to me. It has to do with what is usually known as the Zippe centrifuge, although its designer, Gernot Zippe, once told me that he preferred to call it the Russian centrifuge. Zippe was born in 1917 in what was then Austria-Hungary. After obtaining a degree in physics from the University of Vienna in 1938, Zippe joined the Luftwaffe as a flight instructor and researcher. In the early 1940s, he began studying mechanical engineering at the University of Munich and joined a team dedicated to isotope separation, eventually becoming the group's leader. Zippe was captured by the Russians at the end of the war and interned at a prisoner-of-war camp for German scientists in the outskirts of Moscow. In the summer of 1946, he was sent to a research facility near Sukhumi on the Black Sea where he was tasked with designing gas centrifuges that could be used to separate uranium isotopes in uranium hexafluoride gas. ${ }^{13}$

Before arriving in Sukhumi, Zippe had never seen a centrifuge and knew nothing about them. All he had at his disposal was an antiquated Russian model and some equally outdated literature. During the war, the American physicist Jesse Beams successfully separated uranium isotopes using a centrifuge he had developed while working on the Manhattan Project. Despite considerable investment, the project ultimately failed to deliver sufficient quantities of highly enriched uranium. Starting from scratch, Zippe came up with a design that was orders of magnitude more efficient.

In 1956, Zippe was released by the Russians, and the following year in Holland he attended a meeting on centrifuge design. Realizing that his own design was far better than any of the models on display, Zippe joined the centrifuge industry. As Wellerstein notes, the classification of centrifuge designs has always been rather murky. All the gas centrifuges being used for uranium enrichment in Iran, for example, are modified versions of Zippe's original design.

Wellerstein's chapter on the Zippe centrifuge is followed by another dealing with someone else I knew, the theoretical physicist Keith Brueckner, who died in 2014. Brueckner was the most ambitious person I have ever met and his struggles with the AEC make for entertaining reading. Brueckner had some novel ideas about confining plasma using lasers that had potential applications in the efforts to harness controlled fusion for power generation. At the time, Brueckner was working in collaboration with KMS Industries, a private sector organization unconnected to the AEC. 
In 1969, Brueckner applied for three patents and was informed that his work was considered classified. His ideas had, in fact, already been found in connection with the hydrogen bomb program. "All of that previous work was classified," Wellerstein notes, "and the secrecy surrounding the topic meant that someone like Brueckner could argue that his own invention was not only independent, but arguably had been first."14 Undeterred, Brueckner filed a dozen more patent applications. This led to a very entertaining confrontation, one that is well described by Wellerstein. A compromise was eventually reached, but whatever these ideas were, they do not appear to have led to any breakthroughs in controlled fusion research.

The following chapter examines the spread of nuclear secrets and how difficult it might be for a terrorist group, or even a student, to assemble their own device. ${ }^{15}$ As Wellerstein notes, there have been a number of well-publicized incidents involving students. The most celebrated case is that of John Aristotle Phillips, who came up with a design for a bomb while he was an undergraduate at Princeton in the mid-1970s. Phillips was inspired by John McPhee's book The Curve of Binding Energy, a profile of the bomb designer Ted Taylor. ${ }^{16}$ Phillips attempted to fill in some of the deliberate omissions in Taylor's account with the help of Freeman Dyson, who really should have known better. When Bethe saw the design, he dismissed it as worthless. Dyson subsequently claimed that he had only gotten involved to show how easy it was to obtain declassified material in Washington. ${ }^{17}$

All of this, and indeed the rest of Wellerstein's book, confirms what I have long believed to be true: the information needed to make a nuclear weapon has been in circulation for a long time. In his book, Wellerstein discusses the Iranian and Israeli weapons programs. Israel certainly has this information and my guess is that Iran does too. The fissile material needed for such a device is much harder to obtain. In my view, controlling the spread of these weapons involves controlling the production of these materials. "From a technical standpoint," Wellerstein writes, "nuclear weapons should have been very easy to control."

As Oppenheimer understood in 1945, the material pipelines to acquiring nuclear weapons are relatively large, and controlling the uranium enrichment facilities means controlling the spread of the bomb, even in the face of possibly incomplete or non-existent secrecy. That nuclear control has been elusive should give us pause. The problem of controlling nuclear weapons has never been a purely technical one-it is rather, a political problem. And technical solutions to political problems are rarely adequate. ${ }^{18}$

\section{Jeremy Bernstein is Professor Emeritus of Physics at the Stevens Institute of Technology.}

1. John Kennedy et al., "Properties of 94(239)," Physical Review 70, no. 555 (1946), doi:10.1103/PhysRev.70.555. The following explanation was included when the paper was finally published in 1946:

This letter was received for publication on the date indicated but was voluntarily withheld from publication until the end of the war. The original text has been somewhat changed, by omissions, in order to conform to present declassification standards.

2. Alex Wellerstein, Restricted Data: The History of Nuclear Secrecy in the United States (Chicago: University of Chicago Press, 2021), 9.

3. Our meeting was taken up, for the most part, by Teller rehearsing a talk he had prepared for the following afternoon. I found his talk largely incomprehensible-it was something to do with the meson theory of nuclear forcesand not particularly interesting. Just before I left, Teller made the odd remark that it was nice to be doing physics again. It took me a while before I put two and two together. He had been testifying in the hearing which resulted in Robert Oppenheimer losing his security clearance. Teller's carefully crafted negative testimony had been decisive. When the physics community found out about what he had done, Teller became a pariah. In his book, Wellerstein provides an excellent account of Oppenheimer's trial, which also turned on his lack of enthusiasm for making a hydrogen bomb as well as his personal morality. Oppenheimer did not defend himself very well. He once told me that during the trial he felt like they were discussing someone else.

4. After the successful test it was Bainbridge who made the oft quoted remark, "Now we're all sons of bitches."

5. The "Q" was short for "Personal Security Questionnaire."

6. While these checks were taking place, I was worried about my great-aunt May. If not an actual member of the Communist party, she was a devoted fellow traveler. Either they never came across her, or they found her too batty to be of interest. Years later when I was writing for the New Yorker, I thought that I would use the Freedom of Information Act to get my clearance document and then write something I was going to call Friends and Neighbors. When I received the file, it was almost entirely redacted and useless for my purposes.

7.

The main attraction [was] the promised revelation of secret fusion research by the United States, Great Britain and the Soviet Union, i.e. the talks of the leading fusion scientists Hannes Alfven, Lev Artsimovich, Ludwig Biermann, Peter Thonemann and Edward Teller on "the possibility of controlled fusion."

Sabina Griffith, “Two Weeks in September, 1958: Atoms for Peace Conference in Geneva," ITER Newsline, Sept. 1, 2008.

8. It turned out that some mathematically inclined soldiers had analyzed casino blackjack and found a way to beat 
the dealer. It was written up and had been analyzed by the people at Los Alamos by playing hundreds of thousands of hands on a computer. A little card had been issued which you could bring to the casino and try your luck.

9. Wellerstein, Restricted Data, 57.

10.

Those with yellow badges, such as security details, could enter the technical areas of the lab but were not to be told any classified information at all. Blue badges were for clerks and warehouse employees who would need to know some classified information, like schedules and rosters and names, but would not be allowed access to technical information. Red badges were for technicians and secretaries whose access to information could be quite deep within the scope of their own job but could never exceed it.

Wellerstein, Restricted Data, 57.

11. An interesting story note about Einstein is that he had not heard of fission when Szilard gave him the letter in 1939. It had been discovered a year earlier and was a sensation among physicists, including Einstein's colleagues John Wheeler and Niels Bohr at Princeton, who had created the first general theory of fission. In his later life, Einstein had little interest in ordinary physics.

12. Alfred McCoy, "How an Article about the H-Bomb Landed Scientific American in the Middle of the Red Scare," Scientific American, September 1, 2020, doi:10.1038/scientificamerican0920-73.

13. For further details, see my essay "A Nuclear Supermarket" in Physicists on Wall Street and Other Essays on Science and
Society (New York: Springer, 2008), 52. For a more detailed account of Zippe's transfer to Sukhumi and the work in which he was involved, see Pavel Oleynikov, "German Scientists in the Soviet Atomic Project," The Nonproliferation Review 7, no. 2 (2000): 1-30, doi:10.1080/10736700008436807. The weapons research program at Agudzera near Sukhumi led to the creation of the Sukhumi Institute of Physics and Technology. The institute split in two after the conflict between Georgia and Abkhazia in the early 1990s. Some of its people and programs were relocated to the Georgian capital, Tbilisi, to form the Ilia Vekua Sukhumi Institute of Physics and Technology.

14. Wellerstein, Restricted Data, 327 .

15. I once advised a high school student who was trying to make a small fusion reactor in his garage. He was certainly not trying to make a bomb, but he did get some neutrons out of his device, showing that there had indeed been fusion.

16. Taylor was my boss when I consulted on the Orion spaceship project. For more about this project, a brief biographical sketch of Taylor, and some remarks from Freeman Dyson, see my essay "Reflections on Project Orion," Inference: International Review of Science 5, no. 2 (2020), doi:10.37282/991819.20.4.

17. When my friend, the Pakistani physicist Riazuddin (he had only one name), was put in charge of the attempt to make a nuclear weapon, he took a sabbatical at the University of Maryland so that he could be close to Washington and take advantage of the declassified material.

18. Wellerstein, Restricted Data, 410.

DOI: $10.37282 / 991819.21 .15$ 